\title{
Seasonal occurrence of fin whale song off Juan Fernandez, Chile
}

\author{
Susannah J. Buchan ${ }^{1,2,3, *}$, Laura Gutierrez ${ }^{4}$, Naysa Balcazar-Cabrera ${ }^{1}$, \\ Kathleen M. Stafford ${ }^{5}$ \\ ${ }^{1}$ Center for Oceanographic Research COPAS Sur-Austral, University of Concepción, Casilla 160-C, Concepción, 4030000, Chile \\ ${ }^{2}$ Centro de Estudios Avanzados en Zonas Áridas (CEAZA), Avenida Ossandón 877, Coquimbo, 1781681, Chile \\ ${ }^{3}$ Woods Hole Oceanographic Institution, Biology Department, Woods Hole, Massachusetts, 02543, USA \\ ${ }^{4}$ Centro de Investigación y Gestión de Recursos Naturales (CIGREN), Universidad de Valparaíso, Gran Bretaña 1111, \\ Valparaíso, 2340000, Chile \\ ${ }^{5}$ Applied Physics Laboratory, University of Washington, Seattle, Washington, 98105, USA
}

\begin{abstract}
Fin whales Balaenoptera physalus were the species of baleen whale most widely caught by commercial whaling fleets off the Chilean coast and are globally classified as Endangered. However, very little is known about the present distribution and seasonal movements of fin whales off the coast of Chile. Passive acoustic data collected at the HA03 station of the Preparatory Commission for the Comprehensive Nuclear Test Ban Treaty Organization off the Juan Fernandez Archipelago (JFA) between 2007 and 2016 were analyzed. The temporal occurrence of fin whale song was examined using automatic detection via spectrogram crosscorrelation of song notes and by calculating the average acoustic power in the frequency bands of fin whale song. Fin whale song off JFA was composed of regular $17 \mathrm{~Hz}$ notes associated with high-frequency components at $85 \mathrm{~Hz}$, with singlet phrasing at a dominant primary inter-note interval of $14.4 \mathrm{~s}$ and a secondary interval of $30.8 \mathrm{~s}$. There was a clear seasonal pattern in acoustic presence that was consistent across all years: low or no song during the austral summer and a peak in song occurrence in austral winter. A propagation loss model estimated the detection range at this site to be $186 \mathrm{~km}$. Where the fin whales that are heard off JFA spend the summer months remains an open question. Possible locations include the Western Antarctic Peninsula and/or off northern-central mainland Chile. Further studies should be pursued to better understand the distribution and seasonal movements and to support the conservation of this Endangered species.
\end{abstract}

KEY WORDS: Fin whale $\cdot$ Balaenoptera physalus $\cdot$ Juan Fernandez $\cdot$ Chile $\cdot$ Southeast Pacific Passive acoustic monitoring

\section{INTRODUCTION}

Fin whales Balaenoptera physalus were the species of baleen whale most widely caught by commercial whaling fleets off the Chilean coast, comprising $46.9 \%$ of all catches, totaling 4512 individuals between 1929 and 1983 (Aguayo-Lobo et al. 1998).

${ }^{*}$ Corresponding author: sbuchan@udec.cl;

sjbuchan@gmail.com
Most catches off the Chilean coast were concentrated in central and northern Chile around $35^{\circ} \mathrm{S}, 32^{\circ} \mathrm{S}$, and $19^{\circ} \mathrm{S}$ (Aguayo-Lobo et al. 1998). Although this species has been assessed as Endangered worldwide by the International Union for Conservation of Nature (IUCN) (Reilly et al. 2013), as well as by Aguayo-Lobo et al. (1998) in Chilean waters, very

○ The authors 2019. Open Access under Creative Commons by Attribution Licence. Use, distribution and reproduction are unrestricted. Authors and original publication must be credited. 
little is known about the distribution or seasonal movements of fin whales off the coast of Chile or through the southeast Pacific.

Fin whales off Chile are thought to be part of a population that migrates to the Southern Ocean (Clarke et al. 1978); however, no recent studies have examined this migration in detail. Sightings of fin whales have occurred off central Chile (approximately $33^{\circ}$ to $40^{\circ} \mathrm{S}$ ), but also off northern and southern Chile, the Juan Fernandez Archipelago (JFA), and Easter Island (Aguayo-Lobo et al. 1998 and references therein). Off coastal northern-central Chile, in the waters surrounding Isla Chañaral, which form part of the coastal islands that make up the Humboldt Penguin National Reserve $\left(\sim 29^{\circ} \mathrm{S}\right)$, high summertime aggregations of fin whales have been reported feeding off Humboldt Current krill Euphausia mucronata (Capella et al. 1999, Perez et al. 2006, Toro et al. 2016). Outside of these summertime sightings of fin whales, the question of where fin whales spend the rest of the year remains unknown.

Passive acoustic monitoring (PAM) is a widely used method to examine the temporal and spatial distribution of large whales throughout the world's oceans, including for fin whales (e.g. Watkins et al. 2000, Stafford et al. 2009, Širović et al. 2015). Male fin whales are known to produce song in loud repetitive sequence of notes around $20 \mathrm{~Hz}$ (hereafter referred to as $20 \mathrm{~Hz}$ notes; Watkins et al. 1987, Charif et al. 2002, Croll et al. 2002, Śirović et al. 2007). Associated with the $\sim 20 \mathrm{~Hz}$ note, fin whales in some areas produce a high-frequency component (HFC). Off the western Antarctic, this occurs around $85 \mathrm{~Hz}$ (recorded in 2014; Baumann-Pickering et al. 2015) and $89 \mathrm{~Hz}$ in 2003 (Širović et al. 2009), and off the eastern Antarctic around $99 \mathrm{~Hz}$ (Širović et al. 2009), suggesting that these HFC may serve as possible population identifiers (Gedamke \& Robinson 2010). Fin whales also produce high-frequency notes, sometimes with, and sometimes without, a $20 \mathrm{~Hz}$ note; in the North Atlantic, these occur around 135 to $140 \mathrm{~Hz}$ (Simon et al. 2010, Castellote et al. 2012).

Another fin whale song characteristic which might be a population identifier - albeit a dynamic oneis the duration of the intervals between $20 \mathrm{~Hz}$ notes, the inter-note interval (INI), which is sometimes also referred to as the inter-pulse interval. Hatch \& Clark (2004) found that INI was the most distinguishing characteristic among regional songs. The $20 \mathrm{~Hz}$ notes can occur in singlets, doublets or triplets (Širović et al. 2017 and references therein) with varying INIs. Depending on location, INIs vary from 9 to $34 \mathrm{~s}$ (Thompson et al. 1992, Hatch \& Clark 2004, Delarue et al. 2009, Castellote et al. 2012, Oleson et al. 2014, Širović et al. 2017). Seasonal changes in INIs have been reported: In the northeast Pacific, INIs were found to be shorter in summer and increase progressively over the winter but are then reset annually (Oleson et al. 2014, Śirović et al. 2017); in the western North Atlantic, INIs were short (9.6 s) in late summer to early winter and long (15.1 s) in spring (Morano et al. 2012). Lastly, annual increases in INI have been reported in the northeast Pacific at a rate of $0.54 \mathrm{~s} \mathrm{yr}^{-1}$ over a decade (Weirathmueller et al. 2017).

Although the temporal (seasonal, inter-annual) variation in fin whale singing behavior is clearly dynamic and only now becoming better understood, examining fin whale song in time and space has proven to be a useful approach for achieving a broad understanding of presence/absence and seasonal residence patterns of vocal animals (Širović et al. 2004, 2009, Stafford et al. 2009, Morano et al. 2012, Weirathmueller et al. 2013, Sciacca et al. 2015). In the Southern Ocean, fin whale song occurrence is between February and May, during the austral summer and autumn (Širović et al. 2004). In the Northern Hemisphere, fin whale song is recorded from boreal autumn through spring usually peaking during the boreal winter (Watkins et al. 2000, Stafford et al. 2009, Simon et al. 2010, Nieukirk et al. 2012, Weirathmueller et al. 2017). An exception is the Mediterranean Sea, in which song peaks between spring and summer months (Sciacca et al. 2015). Fin whale song seasonality has not been determined for any sites in the South Pacific.

The Preparatory Commission for the Comprehensive Nuclear Test Ban Treaty Organization (CTBTO; www.ctbto.org) has an International Monitoring Station called HA03, located $\sim 670 \mathrm{~km}$ west of mainland Chile, on Robinson Crusoe Island, part of the JFA. HA03 has 6 hydrophones that collect acoustic data for the primary purpose of detecting underwater explosions. In this study, we examine passive acoustic data from a single hydrophone collected at the HA03 station to determine the temporal variation of fin whale $20 \mathrm{~Hz}$ song occurrence in order to gain an understanding of the seasonal distribution of fin whales off Juan Fernandez in the southeast Pacific. We also provide an estimate of detection range to determine the geographic area acoustically monitored by the HA03 station. Although our aim here is not to provide a detailed description of song characteristics, we examine the presence of $\mathrm{HFC}$, INI, and any possible changes in frequency of song notes and HFC over time. This is the first report of fin whale vocalizations and seasonal occurrence from this region. 


\section{MATERIALS AND METHODS}

\subsection{Acoustic data from the Juan Fernandez Archipelago}

Passive acoustic data (42 $704 \mathrm{~h}$ ) were collected continuously at a $250 \mathrm{~Hz}$ sample rate by a bottommounted hydrophone at $813 \mathrm{~m}$ depth at the HA03 station off JFA (Fig. 1). These data were made available from the CTBTO through the Chilean Nuclear Energy Commission in Santiago, Chile. Acoustic data from a single hydrophone, i.e. the North Station Node 1 at $33^{\circ} 27^{\prime} 28.8^{\prime \prime} \mathrm{S}, 78^{\circ} 56^{\prime} 2.8^{\prime \prime} \mathrm{W}$, were used for this analysis. Data from 2007-2009 and 2014-2016 were analyzed; no data were available between 27 February 2010 and 22 April 2014 due to a tsunami that hit the Chilean coast and the JFA on 27 February 2010 destroying the HA03 station, which was eventually repaired in April 2014. Prior to the 2010 tsunami, the hydrophone used had a sensitivity of $561.81 \mu \mathrm{Pa}$ per digital count; after the tsunami, the replacement hydrophone had a sensitivity of $558.9 \mu \mathrm{Pa}$ per digital count.

\subsection{Median power spectral density analysis}

Each year of data was first examined using median power spectral density (PSD) plots made using PAMGuide (Merchant et al. 2015) to gain a broad view of the acoustic environment and examine the frequencies at which acoustic power occurred, including the frequency bands where we expected fin whale calls to occur: around $20 \mathrm{~Hz}$ and around $89 \mathrm{~Hz}$ or $99 \mathrm{~Hz}$ (Širović et al. 2009). PSD analysis provides the acoustic power expressed in sound pressure level in $1 \mathrm{~Hz}$ frequency bands ( $\mathrm{dB}$ re: $1 \mu \mathrm{Pa}^{2} \mathrm{~Hz}^{-1}$ ); the $50 \%$ percentile (median) of the PSD was then calculated and plotted, identifying peaks in acoustic power around $17 \mathrm{~Hz}$, assumed to be fin whales; $24 \mathrm{~Hz}$, assumed to be southeast Pacific blue whales (Buchan et al. 2014, 2015); and $86 \mathrm{~Hz}$ assumed to be fin whales (Fig. 2). The frequencies of these peaks were used to inform the subsequent analyses described below. Median PSD per year allowed us to visually determine the frequency bands of interest for the $17 \mathrm{~Hz}$ notes and $85 \mathrm{~Hz} \mathrm{HFC}$, i.e. $16-22 \mathrm{~Hz}$ and $84-86 \mathrm{~Hz}$, respectively.

\subsection{Fin whale acoustic power over time}

To examine fin whale song occurrence over time for each year of data, we examined the average power

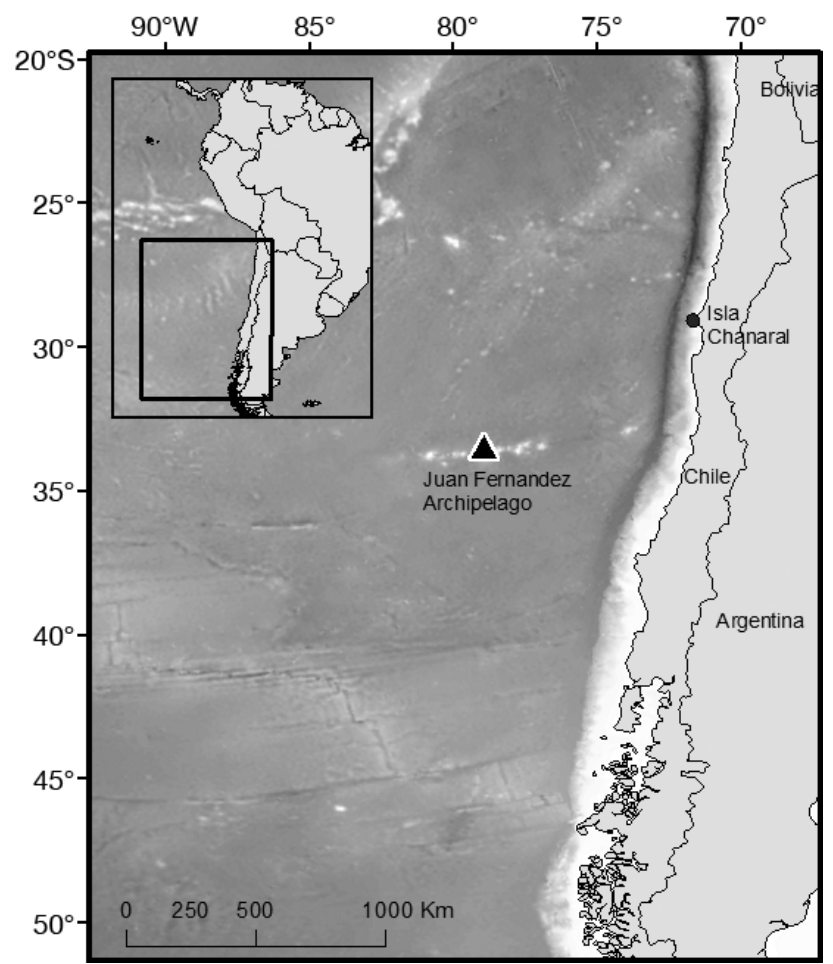

Fig. 1. Study area and location (black triangle) of CTBTO HA03 station off Juan Fernandez

around the $17 \mathrm{~Hz}$ and the $85 \mathrm{~Hz}$ frequency bands. Based on the median PSD plot (Fig. 2), we defined the fin whale bands of interest as being $16-22 \mathrm{~Hz}$ for the $17 \mathrm{~Hz}$ note and $84-86 \mathrm{~Hz}$ for the $85 \mathrm{~Hz}$ HFC. These ranges should account for any possible frequency shift within the year and also avoid the $24 \mathrm{~Hz}$ southeast Pacific blue whale frequency band. We confirmed the frequency range of interest around $17 \mathrm{~Hz}$ and $86 \mathrm{~Hz}$ by measuring the peak frequencies of 100 individual fin whale song pulses around $17 \mathrm{~Hz}$ and 100 song pulses around $86 \mathrm{~Hz}$, using Raven Pro 1.4 (Bioacoustics Research Program 2014). Pulses were selected from different pulse trains spread over a week of data. The $17 \mathrm{~Hz}$ pulses were found to range between 16.6 and $24.4 \mathrm{~Hz}$ with an average center frequency of $18.9 \pm 2.6 \mathrm{~Hz}$. The $86 \mathrm{~Hz}$ pulses were found to range between 83.0 and $87.5 \mathrm{~Hz}$ with an average center frequency of $85.3 \mathrm{~Hz} \pm 0.8 \mathrm{~Hz}$, which supports the choice of fin whale bands at $16-22 \mathrm{~Hz}$ for the $17 \mathrm{~Hz}$ note and $84-86 \mathrm{~Hz}$ for the $85 \mathrm{~Hz} \mathrm{HFC}$.

From the PSD output data (hourly average of acoustic power in $1 \mathrm{~Hz}$ frequency bands), we examined fin whale acoustic power in the $16-22 \mathrm{~Hz}$ band over time in a stepwise manner for each hourly bin: we (1) calculated average acoustic power per $1 \mathrm{~Hz}$ frequency band over the 16 to $22 \mathrm{~Hz}$ bands ('16$22 \mathrm{~Hz}$ band'); (2) calculated average acoustic power 


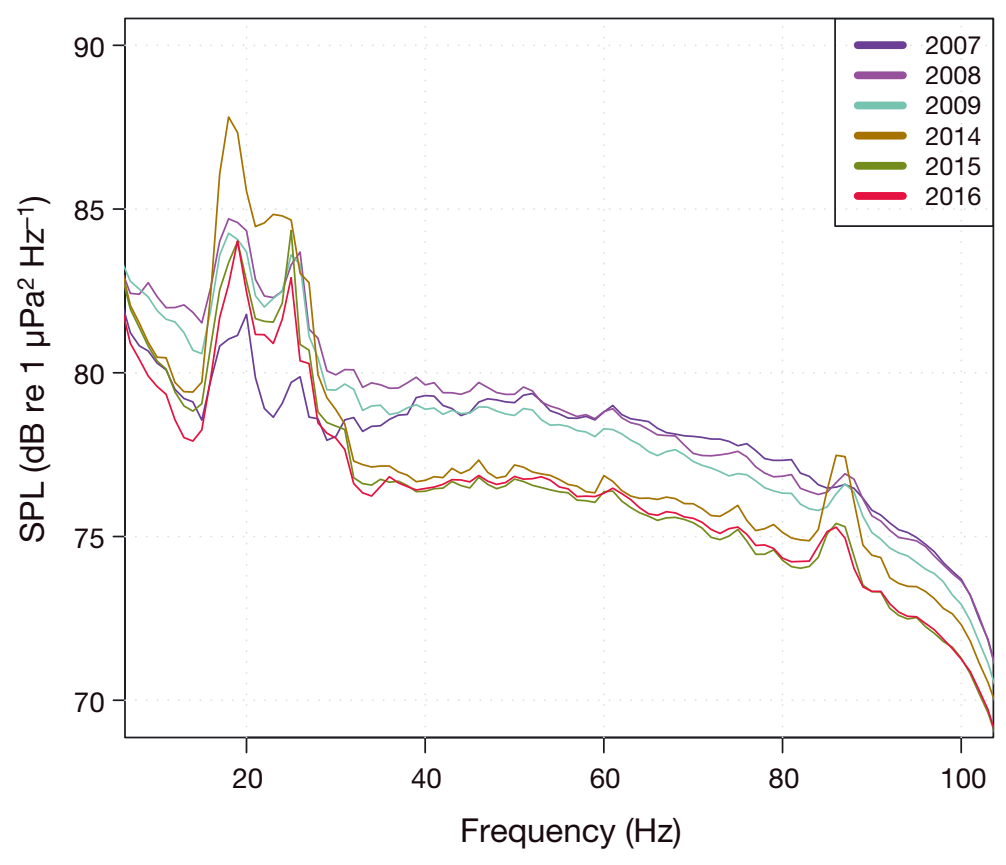

Fig. 2. Median (50\% percentile) of the power spectral density expressed as sound pressure level in $\mathrm{dB}$ re: $1 \mu \mathrm{Pa}^{2} \mathrm{~Hz}^{-1}$, per year of acoustic data (2007-2009 and 2014-2016) off Juan Fernandez, Chile. Note the peaks at around $17 \mathrm{~Hz}$ (fin whales), $24 \mathrm{~Hz}$ (southeast Pacific blue whales) and $86 \mathrm{~Hz}$ (fin whales)

per $1 \mathrm{~Hz}$ frequency band in the 10 and $35 \mathrm{~Hz}$ frequency bands ('ambient noise band'); (3) subtracted the ambient noise band (i.e. the average of the 10 and $35 \mathrm{~Hz}$ bands) from the $16-22 \mathrm{~Hz}$ band to obtain fin whale power in the $16-22 \mathrm{~Hz}$ band for each hour. The 10 and $35 \mathrm{~Hz}$ bands were chosen as ambient noise bands because they are outside the frequencies where fin or blue whale songs can be expected and therefore can be considered representative of background noise levels around the $17 \mathrm{~Hz}$ note band of interest. The same steps were taken to examine the fin whale acoustic power in the $84-86 \mathrm{~Hz}$ band: we (1) calculated average acoustic power per $1 \mathrm{~Hz}$ frequency band over the 84-86 $\mathrm{Hz}$ bands ('84-86 Hz band'); (2) calculated average acoustic power per $1 \mathrm{~Hz}$ frequency band in the $70 \mathrm{~Hz}$ and $100 \mathrm{~Hz}$ frequency bands ('ambient noise band'); (3) subtracted the ambient noise band (i.e. the average of the 70 and $100 \mathrm{~Hz}$ bands) from the $84-86 \mathrm{~Hz}$ band to obtain fin whale acoustic power in the $84-86 \mathrm{~Hz}$ band for each hour. Here, 70 and $100 \mathrm{~Hz}$ bands were con- sidered representative of background noise near the $85 \mathrm{~Hz}$ note band of interest (e.g. Nieukirk et al. 2012). Monthly fin whale acoustic power in the $16-22 \mathrm{~Hz}$ band and the 84-86 Hz band were then calculated and plotted over time for each year of the study period.

\subsection{Automatic detection of fin whale song notes over time}

An alternative method for examining fin whale song occurrence over time was also used, which involved counting individual $17 \mathrm{~Hz}$ song notes using an automatic detection method based on spectrogram cross-correlation (Mellinger \& Clark 2000). Spectrogram cross-correlation measures the similarity between an acoustic signal and a template, or kernel, of the target signal, both of which are represented as a spectrogram. Detection occurs when the time-frequency features of the input signal closely match those of the template and exceed a detection threshold based on a correlation score between the template and the detected signal (Mellinger \& Clark 2000). XBAT (Extensible Bioacoustic Tool; Bioacoustics Research Program 2012) was used to carry out automatic detection, and spectrograms were made with a 512 point FFT, $25 \%$ overlap, and a Hann window. The detector template was a single $17 \mathrm{~Hz}$ song note selected from the acoustic data (Fig. 3). The detector was configured to prevent any esoverlapping detections to avoid double detections of the same sound.

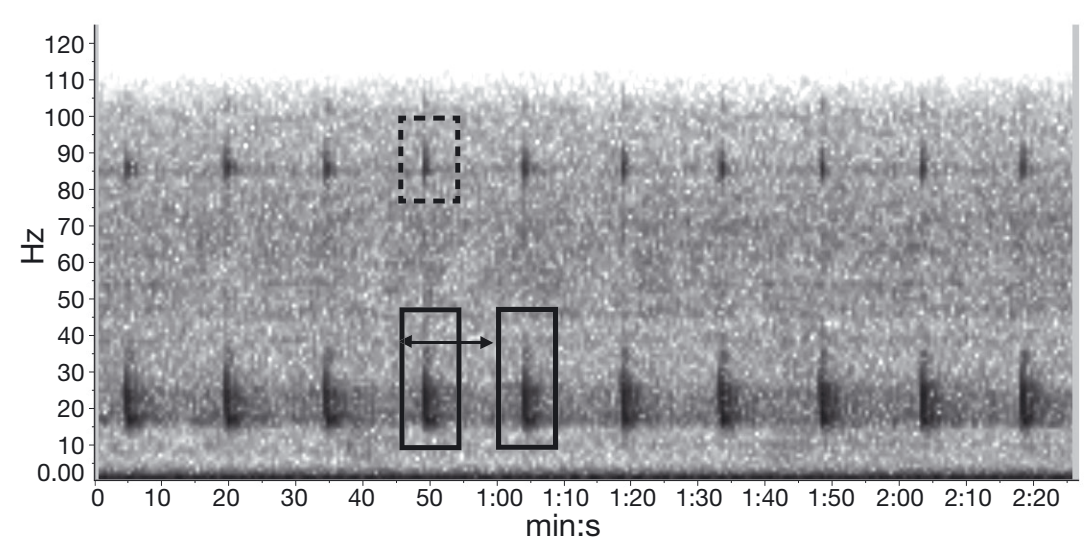

Fig. 3. Spectrogram of $17 \mathrm{~Hz}$ (solid box) and $85 \mathrm{~Hz}$ (dashed box) notes of a fin whale song sequence. Spectrogram parameters: FFT: 256 samples, $25 \%$ overlap, Hann window. Note: The solid black boxes mark the data template used for automatic detection of $17 \mathrm{~Hz}$ notes using spectrogram cross-correlation. The double arrow shows how the inter-note interval was determined, i.e. the duration between the beginning of 2 consecutive detections 
To assess the detector performance, all detections with a minimum correlation score of $20 \%$ from a randomly selected $1.6 \%$ (668 h) subset of the entire 2007-2016 data set were examined manually by an experienced analyst to visually check for true positives (correct detections) and false positives (false detections). Detections with scores below $20 \%$ were extremely numerous and largely false, and therefore were discarded a priori to make efficient use of analyst time. From this, detector precision was determined for correlations above $20 \%$; in principle, the higher the correlation score, the greater the match between the detected signal and the template (as per Roch et al. 2011). Precision is the percentage of all target signals identified by the analyst (true and false positives) that are correctly identified by the automatic detector (true positives). Precision was determined by manually reviewing 96393 individual $17 \mathrm{~Hz}$ notes. When choosing the detection threshold, priority was given to a low false positive rate and a high true positive rate, with a trade-off producing a very high false negative rate, higher detector precision and lower detector recall. Fig. 4 shows precision vs. recall at a range of detection scores (20 to $80 \%$ ); a threshold of $55 \%$ correlation was ultimately chosen. At $55 \%$ detection score, $88.4 \%$ of detections were true positives, $11.6 \%$ were false positives, the precision was 0.88 , and the recall was $0.38 \%$. Precision was assessed seasonally for all years: autumn precision was $95.4 \%$; winter

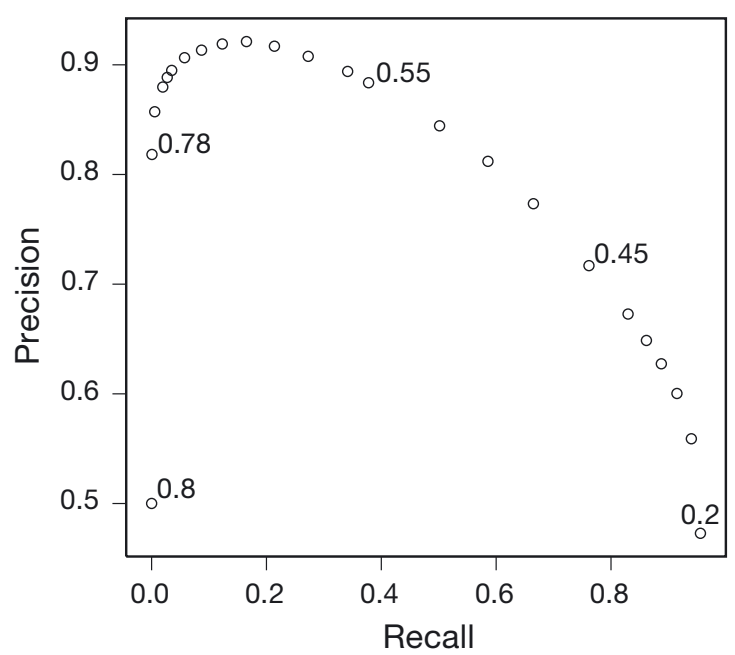

Fig. 4. Performance of automatic detector of $17 \mathrm{~Hz}$ fin whale pulses via spectrogram cross-correlation at detection threshold scores between 0.20 and 0.80 (numbers indicate detection score of points). Precision and recall values are based on the manual review of 96393 fin whale $17 \mathrm{~Hz}$ pulses. The 0.55 threshold was chosen for the detector applied to the entire data set precision was $88.3 \%$; spring precision was $66.7 \%$. There were no detections that met our criteria during summer. Precision was also assessed before and after the 2010 tsunami and subsequent instrument change: for the 2007-2009 period, precision was $96.4 \%$; for the 2014-2016 period, precision was $87.7 \%$. All raw detections at or above $55 \%$ detection score were analyzed; these were not corrected for seasonal differences or pre-/post-tsunami differences in detector performance.

The detector was then applied to the entire dataset, and the number of detections per month was divided by the number of hours of PAM effort to get song note rates (i.e. $17 \mathrm{~Hz}$ note detections per hour of PAM effort) for each month plotted as a histogram.

\subsection{Inter-note interval estimate}

An estimate of INI was done using $17 \mathrm{~Hz}$ note detections. Detection via spectrogram cross-correlation occurs when features of the input signal match those of a template (Mellinger \& Clark 2000), which in this case contained the target signal (a single $17 \mathrm{~Hz}$ note) but also a portion of time before and after the target signal (see Fig. 3). The target signal in the template aligns with the peak correlation with the detected target signal in the time domain. This means that all peak detections of target signals occur at the same time from the start of the detection event. We assumed that the time period between the start of consecutive true positive detections can be taken as an estimate of the duration between 2 consecutive target signals. Therefore, the time from the start of detection $i$ to the start of detection $i+1$ was equivalent to the time from the center of the detected signal $i$ to the center of signal $i+1$. INI was calculated as the duration between the begin time of successive detections (Fig. 3). We took all the 42317 visually checked true positive detections (see Section 2.4) across all years of data to estimate INI. We then plotted these INIs as a histogram for INIs between 0 and $60 \mathrm{~s}$. Caveats include that it is unlikely that all consecutive pulses in a pulse train were successfully detected (given the detection score of $55 \%$ ), and it was also possible that 2 consecutive detections were actually from 2 different but overlapping pulse trains. Therefore, the interval between 2 consecutive detections may not always accurately reflect the interval between 2 consecutive notes in a single pulse train, which can introduce error into the INI estimate. However, because 
of the large sample size used, this approach nevertheless provided a satisfactory first assessment of INI.

\subsection{Detection range of fin whale $17 \mathrm{~Hz}$ notes at the HA03 station}

To determine the detection range of fin whale song notes at the HA03 North Station Node 1 hydrophone, a range-dependent acoustic model (RAM; Collins 1993) was run using the HARCAM envelope (Hodgson and RAM Composite Acoustic Model) propagation loss tool (@) Ocean Acoustic Developments 2017; http://oad.tv). For this, the figure of merit (FOM) was first determined, which is the allowable propagation loss that a signal can suffer and still be detected $50 \%$ of the time, calculated as: $\mathrm{FOM}=\mathrm{SL}-\mathrm{NL}+\mathrm{DI}-\mathrm{DT}$, where SL is the source level assumed to be $189 \pm 4 \mathrm{~dB}$ re: $1 \mu \mathrm{Pa}$ at $1 \mathrm{~m}$ over $20 \mathrm{~Hz}$ (from Širović et al. 2007); NL is noise level assumed to be $80 \mathrm{~dB}$ re: $1 \mu \mathrm{Pa}$ at $1 \mathrm{~m}$ based on Lawrence (2004); DI is a directivity index, assumed to be zero for an omnidirectional hydrophone sensor; DT is the detection threshold, assumed to be $12 \mathrm{~dB}$ re: $1 \mu \mathrm{Pa}$ at $1 \mathrm{~m}$ based on Ainslie (2010). This produces a FOM of $97 \mathrm{~dB}$, meaning that detection is possible $50 \%$ of the time when the propagation loss of the signal is less than the FOM, i.e. $<97 \mathrm{~dB}$.

The RAM in HARCAM models the propagation loss of fin whale $17 \mathrm{~Hz}$ notes with the following assumed inputs: geographical position $=33^{\circ} 27^{\prime}$ $28.8^{\prime \prime} \mathrm{S}, 78^{\circ} 56^{\prime} 2.8 \mathrm{~W}$; month = July; source depth = $10 \mathrm{~m}$ (taken from Stimpert et al. 2015); omnidirectional hydrophone deployment depth $=813 \mathrm{~m}$; source frequency $=20 \mathrm{~Hz}$; FOM $=97 \mathrm{~dB}$. Water column temperature and salinity data were obtained from the World Ocean Atlas 2013 (www.nodc.noaa.gov/OC5/ woa13/); bathymetric data from the General Bathymetric Chart of the Oceans V3 (GEBCO; www.gebco. net); water-sediment interface data from HFEVA (High Frequency Environmental Acoustics Sediment Model); Sediment type and thickness were provided by WADER (http://oad.tv). All data were compiled by Ocean Acoustic Developments. Because the seasonal variation in oceanographic conditions was minimal, causing only a very small variation in sonic layer depth (only between 10 and $56 \mathrm{~m}$ depth throughout the year), the sonic layer is essentially transparent for $20 \mathrm{~Hz}$ signals, and therefore different seasonal propagation models were not determined and water column input data for the month of July were used.

\section{RESULTS}

\subsection{Median power spectral density analysis}

The median PSD plot identified peak acoustic power produced by fin whales at 17 and $85 \mathrm{~Hz}$ (Fig. 2). Note that the peak at $24 \mathrm{~Hz}$ that can be attributed to southeast Pacific blue whales (e.g. Buchan et al. 2015). The PSD plot indicates no frequency shift in the $17 \mathrm{~Hz}$ note over the study period, but a slight shift in the frequency of the $85 \mathrm{~Hz}$ HFC was apparent, from $87 \mathrm{~Hz}$ in 2007 to $85 \mathrm{~Hz}$ in

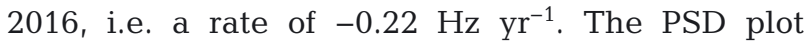
revealed a clear difference in overall noise levels between 2007, 2008, 2009 which all displayed high ambient noise conditions around $-20 \mathrm{~dB}$ re: $1 \mu \mathrm{Pa}^{2}$ $\mathrm{Hz}^{-1}$ at $30 \mathrm{~Hz} ; 2016$ had intermediate noise conditions around $-35 \mathrm{~dB}$ re: $1 \mu \mathrm{Pa}^{2} \mathrm{~Hz}^{-1}$ at $30 \mathrm{~Hz}$; and 2014 and 2015 had low noise conditions around

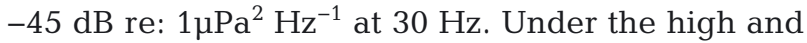
intermediate noise conditions, the peaks at 17 and $85 \mathrm{~Hz}$ are less pronounced than under low noise conditions.

\subsection{Fin whale song rates and acoustic power over time}

A total of 1241958 fin whale $17 \mathrm{~Hz}$ notes were detected in the CTBTO's Juan Fernandez HA03 passive acoustic data between 2007 and 2009 (636 250) and between 2014 and 2016 (605 708). Monthly detection rates, across years, ranged between 0 and 94 detections per hour of effort (bars in Fig. 5).

The seasonal pattern in acoustic power (at both 17 and $85 \mathrm{~Hz}$ ) (lines in Fig. 5) and in monthly $17 \mathrm{~Hz}$ note detections was consistent across years: very few or no detections during December, January, February, and March, i.e. the austral summer; and higher detections between June (the onset of winter) and September (early spring), with a clear peak in August, i.e. during the austral winter.

\subsection{INI and detection range}

The INI histogram shows a bimodal distribution, with a primary peak centered at $14.4 \mathrm{~s}$ and a secondary peak at $30.8 \mathrm{~s}$. The dominant INI was $14.4 \mathrm{~s}$, but this ranged from 13.4 to $16.4 \mathrm{~s}$ (Fig. 6).

From the HARCAM propagation loss modelling, the detection range of the fin whale song notes at the hydrophone was $186 \mathrm{~km}$ for a whale singing at $10 \mathrm{~m}$ 


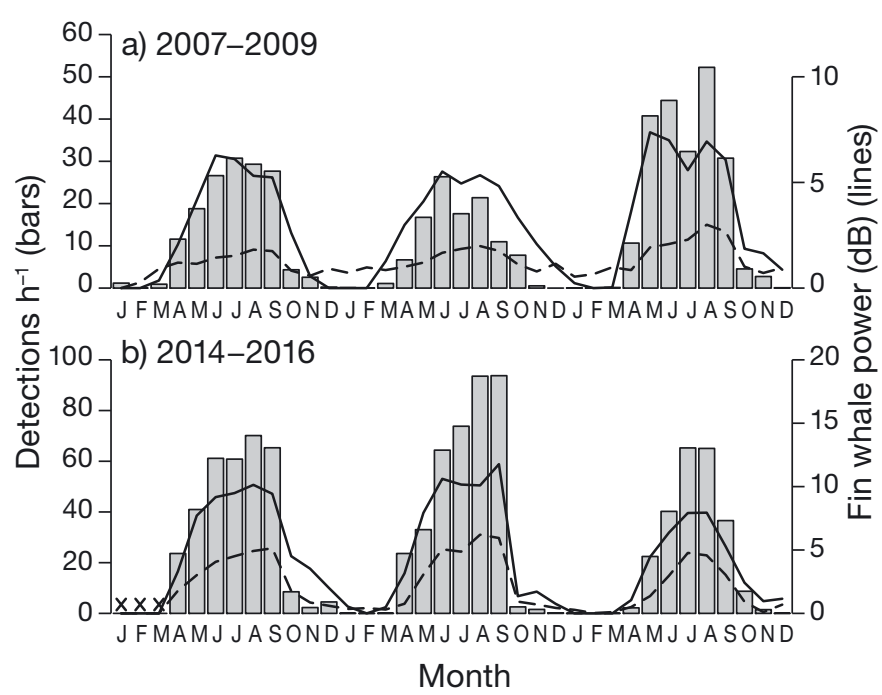

Fig. 5. Monthly fin whale song rates from automatic detections of $17 \mathrm{~Hz}$ notes (detections per hour of passive acoustic monitoring effort; bars) and fin whale acoustic power ( $\mathrm{dB}$ re: $1 \mu \mathrm{Pa}^{2} \mathrm{~Hz}^{-1}$ ) in the $16-22 \mathrm{~Hz}$ frequency band (solid line) and in the $84-86 \mathrm{~Hz}$ frequency band (dashed line) off Juan Fernandez, Chile, during (a) 2007-2009 and (b) 2014-2016. Detections were not corrected for seasonal difference in detector performance (see Section 2). Crosses mark lack of data for these months. Note the different $y$-axis scales

depth. This range decreases to $97 \mathrm{~km}$ when the whale is singing at $5 \mathrm{~m}$ depth and increases to $324 \mathrm{~km}$ when the whale is singing at $20 \mathrm{~m}$ depth.

\section{DISCUSSION}

\subsection{General characteristics of fin whale song off Juan Fernandez}

Fin whale song at the CTBTO Juan Fernandez HA03 station was composed of regular $17 \mathrm{~Hz}$ notes associated with short notes at $\sim 85 \mathrm{~Hz}$ and singlet phrasing at a dominant INI of $\sim 14.4 \mathrm{~s}$. Although the $17 \mathrm{~Hz}$ note is within the general frequency range reported for fin whales (Stafford et al. 1999, Širović et al. 2004, Castellote et al. 2012, Weirathmueller et al. 2017), it is lower than reports in the literature. The $85 \mathrm{~Hz}$ note was similar to that noted for HFC for the Western Antarctic Peninsula from 2014 (BaumannPickering et al. 2015); this value was $89 \mathrm{~Hz}$ in 2003. The possible rate of frequency decrease $(-0.22 \mathrm{~Hz}$ $\mathrm{yr}^{-1}$ ) that we have observed over our $6 \mathrm{yr}$ study period suggests that the 89 and $85 \mathrm{~Hz}$ high pulses may be representative of the same population. A frequency decrease over decadal timescales has recently been documented for fin whales in the north- east Pacific and the southern Indian Ocean (Weirathmueller et al. 2017, Leroy et al. 2018).

The INIs reported here were within the general range of INIs in the literature (Stafford et al. 1999, Širović et al. 2004, 2017, Castellote et al. 2012, Morano et al. 2012, Oleson et al. 2014, Weirathmueller et al. 2017). The primary mode at $14.4 \mathrm{~s}$ is similar to the 13 s INI reported off the Western Antarctic Peninsula in 2003-2004 (Širović et al. 2004). At present, there are no other INIs reported in the literature from other areas in the Southern Hemisphere.

We did not see the apparent complexity recently described for the North Pacific (i.e. singlets, doublets and triplets; Oleson et al. 2014, Širović et al. 2017, Weirathmueller et al. 2017). However, the method we used to estimate INI had drawbacks and was done to provide a first coarse approach to INI estimation, since the aim of this study was not an in-depth examination of singing behavior. Because INI was estimated by calculating the interval between all consecutive detections, it is likely that the detector did not detect all consecutive pulses in a pulse train (particularly with a $55 \%$ detection score applied) and that the detector could have detected 2 pulses very close together from 2 overlapping pulse trains. This means that very large and very small intervals could have been measured between 2 consecutive notes and that this does not reflect the real INI in a single pulse train. We are, however, satisfied with this first estimate given the very large sample size, i.e. $>42000$

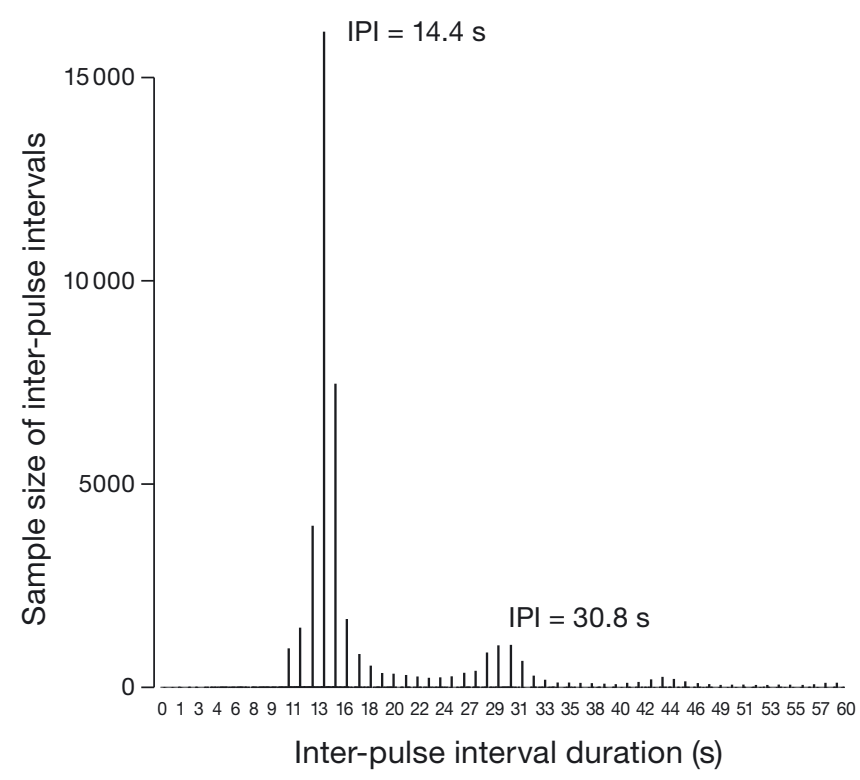

Fig. 6. Inter-note interval (INI) of fin whale song off Juan Fernandez, Chile. INI was calculated as the duration in s between 2 consecutive $17 \mathrm{~Hz}$ note detections (inter-pulse interval duration; IPI) 
detections. Given that INI may be useful as a population identifier, more detailed work is needed to look at seasonal and intra-annual variation of the INI of fin whale song off JFA.

\subsection{Detector performance and ambient noise}

There were clear differences in ambient noise levels between years, i.e. high ambient noise in 2007 , 2008, and 2009, intermediate in 2016, and lower levels in 2014 and 2015 (Fig. 2). There was an instrument change after the 2010 tsunami which may have led to lower overall received levels due to a known incremental drop in sensitivity and/or instrument type. However, this does not explain the difference between 2014-2015 and 2016. Unknown internal factors (e.g. hydrophone sensitivity) or external factors (e.g. deployment platform noise or ambient noise) between years may explain these changes, but this information is not available.

Changes in noise affected the detection of $17 \mathrm{~Hz}$ notes and $85 \mathrm{~Hz}$ HFC via spectrogram cross-correlation and acoustic power. In effect, the energy peaks at 17 and $85 \mathrm{~Hz}$ were less pronounced under high (2007-2009) and intermediate (2016) noise conditions, compared to low noise conditions (2014 and 2015) (Fig. 2). Recall increased and precision decreased after the known instrument change: false negatives decreased, and false positives increased. This means fewer target signals were missed by the detector and more non-target signals were incorrectly detected by the detector under lower noise conditions (2014-2016). Higher noise can explain why the total number of $17 \mathrm{~Hz}$ note detections $\mathrm{h}^{-1}$ and fin whale acoustic power were lower in 20072009 compared to 2014-2016 (Fig. 5). Noise might also explain why the acoustic power in the 16-22 Hz and 84-86 Hz bands were less well-coupled in 2007-2009 compared with 2014-2015, possibly due to noise affecting the higher-frequency band (Fig. 5). The overall impact of changes in ambient noise level is to change the area over which fin whales can be detected off JFA, both for analysis purposes and for the animals themselves. Changes in ambient noise affect the 'acoustic space' over which animals can communicate (e.g. Hatch et al. 2012). Without more information on the hydrophone deployment, we cannot conclusively say whether this noise is due to internal or external factors. However, although overall detections were lower in 2007-2009 compared to 2014-2015, the same seasonal pattern was clear from the data.
There were also seasonal changes in detector precision, which are most likely due to external environmental factors: in spring, recall was highest and precision was lowest, indicating a lower proportion of false negatives and a higher proportion of false positives, compared to autumn when recall was lowest (higher proportion of false negatives) and precision was highest (lower proportion of false positives). Higher levels of ambient noise might be explained in autumn due to adverse weather during the transition between summer and winter. Noise levels (regardless of their source) and changes in detector performance are important to bear in mind when interpreting the temporal changes in $17 \mathrm{~Hz}$ note and $85 \mathrm{~Hz} \mathrm{HFC}$ occurrence in Fig. 5. However, the close agreement between the individual $17 \mathrm{~Hz}$ pulse detections and the fin whale band noise curves gives us confidence in the robustness of the seasonal patterns shown in our data. Because the causes of inter-annual variation in noise remain unresolved, we cannot draw conclusions on the inter-annual changes in animal presence, but rather focus the discussion on the intraannual variation in fin whale song occurrence and animal presence.

\subsection{Fin whale seasonal distribution in the southeast Pacific}

Bearing in mind variations in detector performance between seasons, there was a clear temporal pattern in fin whale detections and acoustic power at the HA03 station which showed a consistent seasonal trend of austral winter acoustic presence of fin whales in the waters around the JFA. Although the low recall rate of the $17 \mathrm{~Hz}$ note automatic detector could have led to underestimation of detections $\mathrm{h}^{-1}$, both the automatic detection analysis and the acoustic power analysis indicate the same seasonal pattern. The estimated maximum detection range of $324 \mathrm{~km}$ was much greater than the detection range for fin whales in the Southern Ocean, on hydrophones deployed at similar depths, which was estimated to be $56 \mathrm{~km}$ (Širović et al. 2007). In the present study, then, we may be listening to whales at a greater distance than that reported by Širović et al. (2007). However, we are still monitoring an area within the Southeast Pacific region rather than listening to animals in the Southern Ocean.

The seasonal trend in fin whale acoustic occurrence points towards some group or population of fin whales that consistently spend the winter in the offshore waters of the southeast Pacific within a few 
$100 \mathrm{~km}$ of the JFA. This does not exclude this group of animals from wintering in other offshore areas that have not yet been visually or acoustically monitored. Where these animals spend the rest of the year remains unknown. It is possible that they move out of this area outside winter months; however, it is also possible that these animals are not vocal outside winter months and therefore undetectable using PAM (Stafford et al. 2007). From recent work off northern Chile (S. J. Buchan et al. unpubl. data), high visual sightings of fin whales during spring and early summer months (November-February) do not coincide with acoustic recordings of fin whale vocalizations, suggesting variation in vocalization production over time.

However, the scenario in which fin whales move out of the JFA area in summer coincides with findings by Sepúlveda et al. (2016) using visual monitoring efforts off Isla Chañaral between 2015 and 2016, who recorded high numbers of foraging fin whales primarily during the austral summer months (December and March). Further, a recent study of fin whales instrumented with satellite tags showed 1 male moving south towards JFA in summer (Sepúlveda et al. 2018). This, as well as previous studies (Capella et al. 1999, Perez et al. 2006, Pacheco et al. 2015, Toro et al. 2016), suggests summertime residency of some fin whales on coastal feeding grounds off central and northern mainland Chile. No long-term passive acoustic data are available for these areas. Interestingly, winter sightings have been reported off the coast of mainland Chile, but at much lower rates than during summer months (Pacheco et al. 2015, Sepúlveda et al. 2016). The results of this study and limited sighting data off mainland Chile could point towards a seasonal longitudinal movement of fin whales onshore-offshore in the southeast Pacific, but more temporal and spatial coverage in this region is necessary for conclusive results.

Alternatively, if we assume that the highfrequency note is a population identifier and that a downward frequency shift of the $89 \mathrm{~Hz}$ note recorded off the Western Antarctic Peninsula in 2003 has occurred, then it is possible that fin whales off JFA (that produce $85 \mathrm{~Hz}$ notes) are part of a population that undertakes a seasonal latitudinal migration between summer feeding grounds off the Western Antarctic Peninsula and wintering grounds in the offshore southeast Pacific (JFA). More recent recordings from the Southern Ocean would be useful to determine whether the $89 \mathrm{~Hz}$ note in Antarctica has decreased in frequency or been maintained.
In either case, at present, we have no evidence that the fin whales sighted off the coast of mainland Chile or observed acoustically off the Western Antarctic Peninsula are the same animals as those heard at the JFA HA03 station. Based on the recovery of 4 out of the 11 whale marks deployed into fin whales off Chile in October and November 1958 by commercial whaling fleets in the Drake Passage (presumably operating during the austral summer), we know that some animals do migrate between the coast of Chile and Antarctica (Clarke et al. 1978 and references therein). It is unclear if this is the predominant seasonal movement of the population of fin whales heard off JFA.

It is also possible that there are 2 partially overlapping populations of fin whales in the southeast Pacific, one that forages in the Southern Ocean and one that forages off mainland Chile during summer, and that both spend the winter offshore in the southeast Pacific. For better-studied blue whales, 2 distinct Chilean and Antarctic blue whale populations are known to overlap in this region, based on morphometrics (Branch et al. 2007), genetics (Torres-Florez et al. 2014), and acoustics (Stafford et al. 1999, Buchan et al. 2014, 2015, 2018). A more detailed comparison of fin whale song characteristics from the southeast Pacific and the Southern Ocean could help elucidate this for fin whales.

This study is the first report of fin whale song in the southeast Pacific and reveals large gaps in the current knowledge of fin whale population structure and seasonal distribution in the southeast Pacific. We recommend further coverage of PAM and sighting effort off the coasts of Chile and Peru, as well as offshore islands like Juan Fernandez, and also acoustic and genetic studies in the southeast Pacific and the Southern Ocean to better understand the distribution, seasonal movements, and population structure of this endangered species.

Acknowledgements. We thank the Preparatory Commission for the Comprehensive Nuclear Test Ban Treaty Organization and the Chilean Commission of Nuclear Energy for proving the data used in this study. S.J.B. and N.B.C. were supported by the Center for Oceanographic Research COPAS Sur-Austral, CONICYT PIA PFB31. S.J.B. was also supported during analysis and writing by the Office of Naval Research Global (awards N62909-16-2214 and N00014-172606), and a grant to the Centro de Estudios Avanzados en Zonas Áridas (CEAZA) 'Proyecto CEAZA, 3er Fortalecimiento de Centros Regionales, Programa Regional CONICYT R16A10003'. Our greatest thanks to John Hodgson $\mathrm{MSc}$, Technical Director at Ocean Acoustic Developments and Adrian Brown of the Defence Science and Technology Laboratory (UK) for carrying out the propagation modelling free of charge. Many thanks to Rex Andrew for his help with 
PSD figure preparation in R. Thanks also go to Nathan Merchant for his kind help with PAMGuide. Many thanks to Michael Pitzrick for his guidance with XBAT. Many thanks to the members of the Southern Ocean Research Partnership Blue and Fin Whale Acoustic Trends Working group for useful discussions that improved the quality of this study.

\section{LITERATURE CITED}

Aguayo-Lobo A, Torres D, Acevedo J (1998) Los mamíferos marinos de Chile: 1. Cetacea. Ser Cient INACH 48:19-159

Ainslie MA (2010) Principles of sonar performance modeling. Springer Praxis, Chichester

Baumann-Pickering S, Širović A, Trickey JS, Hildebrand JA, Reyes Reyes MV, Melcón ML, Iniquez MA (2015) Cetacean presence near Elephant Island, Antarctica, based on passive acoustic monitoring. International Whaling Commission Paper SC/66a/SH/18 (available from https://iwc.int)

Bioacoustics Research Program (2012) Raven Pro: interactive sound analysis software (Version 1.5) [Computer software]. The Cornell Lab of Ornithology, Ithaca, NY. www.birds.cornell.edu/raven

Branch TA, Abubaker EMN, Mkango S, Butterworth DS (2007) Separating southern blue whale subspecies based on length frequencies of sexually mature females. Mar Mamm Sci 23:803-833

Buchan S, Hucke-Gaete R, Rendell L, Stafford KM (2014) A new song recorded from blue whales in the Corcovado Gulf, Southern Chile, and an acoustic link to the Eastern Tropical Pacific. Endang Species Res 23:241-252

Buchan S, Stafford KM, Hucke-Gaete R (2015) Seasonal occurrence of southeast Pacific blue whale songs in southern Chile and the eastern tropical Pacific. Mar Mamm Sci 31:440-458

* Buchan SJ, Hucke-Gaete R, Stafford KM, Clark CW (2018) Occasional acoustic presence of Antarctic blue whales on a feeding ground in southern Chile. Mar Mamm Sci 34: 220-228

Capella J, Vilina Y, Gibbons J (1999) Observation of cetaceans at Isla Chañaral, and new records at the Humboldt Penguin National Reserve, northern Chile. Estud Oceanol (Chile) 18:57-64

Castellote M, Clark CW, Lammers MO (2012) Fin whale (Balaenoptera physalus) population identity in the western Mediterranean Sea. Mar Mamm Sci 28:325-344

Charif RA, Mellinger DK, Dunsmore KJ, Fristrup KM, Clark CW (2002) Estimated source levels of fin whale (Balaenoptera physalus) vocalizations: adjustments for surface interference. Mar Mamm Sci 18:81-98

Clarke R, Aguayo-Lobo A, Basulto del Campo S (1978) Whale observation and whale marking off the coast of Chile in 1964. Sci Rep Whales Res Inst 30:117-182

* Collins MD (1993) A split-step Pad solution for the parabolic equation method. J Acoust Soc Am 93:1736-1742

Croll DA, Clark CW, Acevedo A, Tershy B, Flores S, Gedamke J, Urban J (2002) Only male fin whales sing loud songs. Nature 417:809-811

* Delarue J, Todd SK, Van Parijs SM, Di Iorio L (2009) Geographic variation in northwest Atlantic fin whale (Balaenoptera physalus) song: implications for stock structure assessment. J Acoust Soc Am 125:1774-1782

Gedamke J, Robinson SM (2010) Acoustic survey for marine mammal occurrence and distribution off East Antarctica
(30-80 E) in January-February 2006. Deep Sea Res II 57 : 968-981

Hatch LT, Clark CW (2004) Acoustic differentiation between fin whales in both the North Atlantic and North Pacific Oceans, and integration with genetic estimates of divergence. International Whaling Commission Paper SC/56/SD6 presented to IWC Scientific Comittee, June 2004 (available from secretariat@ iwcoffice.org)

*Hatch LT, Clark CW, Van Parijs S, Frankel A, Ponirakis D (2012) Quantifying loss of acoustic communication space for right whales in and around a U.S. National Marine Sanctuary. Conserv Biol 26:983-994

KLawrence MW (2004) Acoustic monitoring of the global ocean for the CTBT. Proc ACOUSTICS 2004, 3-5 Nov 2004, Gold Coast, p 455-460, www.acoustics.asn.au/ conference_proceedings/AAS2004/ACOUSTIC/PDF/ AUTHOR/AC040084.PDF

* Leroy EC, Samaran F, Stafford KM, Bonnel J, Royer JY (2018) Broad-scale study of the seasonal and geographic occurrence of blue and fin whales in the Southern Indian Ocean. Endang Species Res 37:289-300

* Mellinger DK, Clark CW (2000) Recognizing transient lowfrequency whale sounds by spectrogram correlation. J Acoust Soc Am 107:3518-3529

Merchant ND, Fristrup KM, Johnson MP, Tyack PL, Witt MJ, Blondel P, Parks SE (2015) Measuring acoustic habitats. Methods Ecol Evol 6:257-265

Morano J, Salisbury D, Rice A, Conklin K, Falk K, Clark C (2012) Seasonal and geographical patterns of fin whale song in the western North Atlantic Ocean. J Acoust Soc Am 132:1207-1212

Nieukirk SL, Mellinger DK, Moore SE, Klinck K, Dziak RP, Goslin J (2012) Sounds from airguns and fin whales recorded in the mid-Atlantic Ocean, 1999-2009. J Acoust Soc Am 131:1102-1112

\% Oleson E, Širović A, Bayless A, Hildebrand J (2014) Synchronous seasonal change in fin whale song in the North Pacific. PLOS ONE 9:e115678

*Pacheco AS, Villegas VK, Riascos JM, Van Waerebeek K (2015) Presence of fin whales (Balaenoptera physalus) in Mejillones Bay, a major seaport area in northern Chile. Rev Biol Mar Oceanogr 50:383-389

* Perez MJ, Thomas F, Uribe F, Sepúlveda M, Flores M, Moraga R (2006) Fin whales (Balaenoptera physalus) feeding on Euphausia mucronata in nearshore waters off North-Central Chile. Aquat Mamm 32:109-113

Reilly SB, Bannister JL, Best PB, Brown M and others (2013) Balaenoptera physalus. The IUCN Red List of Threatened Species 2013:e.T2478A44210520. http://dx.doi.org/ 10.2305/IUCN.UK.2013-1.RLTS.T2478A44210520.en (accessed February 2019)

* Roch MA, Brandes TS, Patel B, Barkley Y, Baumann-Pickering S, Soldevilla MS (2011) Automated extraction of odontocete whistle contours. J Acoust Soc Am 130:2212-2223

* Sciacca V, Caruso F, Beranzoli L, Chierici F and others (2015) Annual acoustic presence of fin whale (Balaenoptera physalus) offshore Eastern Sicily, Central Mediterranean Sea. PLOS ONE 10:e0141838

Sepúlveda M, Oliva D, Pavez G, Santos-Carvallo M (2016) Caleta Chañaral de Aceituno: destino turístico de alta calidad para el avistamiento de cetáceos, otros mamíferos y aves marinas. In: Sepúlveda M, Oliva D, Pavez G, Santos-Carvallo M (eds) Editorial Universidad de Valparaíso, Valparaíso 
Sepúlveda M, Perez-Alvarez MJ, Santos-Carvallo M, Pavez G, Olavarria C, Moraga R, Zerbini AN (2018) From whaling to whale watching: identifying fin whale critical foraging habitats off the Chilean coast. Aquat Conserv 28: 821-829

Simon M, Stafford KM, Beedholm K, Lee CM, Madsen PT (2010) Singing behavior of fin whales in the Davis Strait with implications for mating, migration and foraging. $\mathrm{J}$ Acoust Soc Am 128:3200-3210

Šrović A, Hildebrand JA, Wiggins SM, McDonald MA, Moore SE, Thiele D (2004) Seasonality of blue and fin whale calls and the influence of sea ice in the Western Antarctic Peninsula. Deep Sea Res II 51:2327-2344

Širović A, Hildebrand JA, Wiggins SM (2007) Blue and fin whale call source levels and propagation range in the Southern Ocean. J Acoust Soc Am 122:1208-1215

Širović A, Hildebrand JA, Wiggins SM, Thiele D (2009) Blue and fin whale acoustic presence around Antarctica during 2003 and 2004. Mar Mamm Sci 25:125-136

Širović A, Oleson EM, Buccowich J, Rice A, Bayless AR (2017) Fin whale song variability in southern California and the Gulf of California. Sci Rep 7:1-11

Širović A, Rice A, Chou E, Hildebrand JA, Wiggins SM, Roch MA (2015) Seven years of blue and fin whale call abundance in the Southern California Bight. Endang Species Res 28:61-76

Stafford KM, Nieukirk SL, Fox C (1999) Low-frequency whale sounds recorded on hydrophones moored in the eastern tropical Pacific. J Acoust Soc Am 106:3687-3698

Stafford KM, Mellinger DK, Moore SE, Fox CG (2007) Seasonal variability and detection range modeling of baleen whale calls in the Gulf of Alaska, 1999-2002. J Acoust Soc Am 122:3378-3390

Editorial responsibility: Clive McMahon,

Hobart, Tasmania, Australia
Stafford KM, Citta JJ, Moore SE, Daher MA, George JE (2009) Environmental correlates of blue and fin whale call detections in the North Pacific Ocean from 1997 to 2002. Mar Ecol Prog Ser 395:37-53

Stimpert AK, DeRuiter SL, Falcone EA, Joseph J and others (2015) Sound production and associated behavior of tagged fin whales (Balaenoptera physalus) in the Southern California Bight. Anim Biotelem 3:1-12

* Thompson PO, Findley LT, Vidal O (1992) $20 \mathrm{~Hz}$ pulses and other vocalizations of fin whales, Balaenoptera physalus, in the Gulf of California, Mexico. J Acoust Soc Am 92: 3051-3057

Toro F, Vilina YA, Capella JJ, Gibbon J (2016) Novel coastal feeding area for eastern South Pacific fin whales (Balaenoptera physalus) in mid-latitude Humboldt Current waters off Chile. Aquat Mamm 42:47-55

*Torres-Florez JP, Hucke-Gaete R, Rosenbaum H, Figueroa CC (2014) High genetic diversity in a small population: the case of Chilean blue whales. Ecol Evol 4:1398-1412

W Watkins WA, Tyack P, Moore KE, Bird JE (1987) The 20-Hz signals of finback whales (Balaenoptera physalus). J Acoust Soc Am 82:1901-1912

WWatkins WA, Daher MA, Repucci GM, George JE, Martin DL, DiMarzio N, Gannon D (2000) Seasonality and distribution of whale calls in the North Pacific. Oceanography (Wash DC) 13:62-67

*Weirathmueller MJ, Wilcock WSD, Soule DC (2013) Source levels of fin whale $20 \mathrm{~Hz}$ pulses measured in the Northeast Pacific Ocean. J Acoust Soc Am 133:741-749

* Weirathmueller MJ, Stafford KM, Wilcock WSD, Hilmo RS, Dziak RP, Tréhu AM (2017) Spatial and temporal trends in fin whale vocalizations recorded in the NE Pacific Ocean between 2003-2013. PLOS ONE 12:e0186127

Submitted: January 8, 2018 ; Accepted: March 27, 2019 Proofs received from author(s): June 20, 2019 